\title{
A competitividade como fator negativo na aviação brasileira
}

\section{Competitiveness as a negative factor in Brazilian aviation}

\author{
Lucas dos Santos Boneli1, Michele dos Santos Gomes da Rosa² \\ 1 Acadêmico do curso de graduação em Ciências Aeronáuticas pela PUCRS; Piloto Privado. <lucasboneli@terra.com.br> \\ 2 Doutora em Medicina e Ciências da Saúde pela PUCRS (2015); Mestra em Engenharia Elétrica pela mesma faculdade (2007); \\ Especialista em Formação Pedagógica pela Fundação Saint Pastous (2012); Especialista em Fisioterapia Cardiorespiratória pelo Instituto de Cardiologia \\ do Rio Grande do Sul (2010); Especialista em Medicina da Saúde e Ciências da Saúde pela PUCRS (2004); Graduada em Fisioterapia pela Universidade \\ de Cruz Alta (2003). Coordenadora Administrativa do Centro de Microgravidade junto a unidade acadêmica FACA/PUCRS. <michele.rosa@pucrs.br>
}

\begin{abstract}
RESUMO
A competição entre as empresas no mercado aéreo é um importante fator que deve ser levado em consideração quando no estudo da viabilidade de abertura do setor à livre concorrência, visto que essa, quando agindo de modo "predatório", pode levar as companhias aéreas a enfrentar severas crises financeiras, contribuindo assim negativamente para a estabilização desse setor que ainda sofre para se consolidar no país. Sendo assim, realizou-se um levantamento do referencial bibliográfico voltado à história da regulação e desregulação aérea no Brasil, destacando-se seus principais pontos e reflexos na gestão das empresas aéreas, para assim fazer-se uma análise do panorama atual do mercado da aviação brasileira.
\end{abstract}

PALAVRAS-CHAVE: aviação brasileira; processos regulatórios; competição; desregulação.

\begin{abstract}
Competition between companies in the air transport industry is an important factor that should be taken into consideration when studying the feasibility of opening up the sector to free market competition. Acting in a "predatory" manner may cause airline companies to face severe financial crises, thus contributing negatively to the stability of this sector, which is still struggling to consolidate within the country. Therefore, a survey of the bibliographic references focused on the history of air regulation and deregulation in Brazil was conducted, highlighting the main points and their impact on airline management, in order to produce an analysis of the current situation within the Brazilian aviation market.
\end{abstract}

KEYWORDS: Brazilian aviation; regulatory processes; competition; deregulation.

Pontifical Catholic University of Rio Grande do Sul

Porto Alegre, RS, Brazil

Editor

Thaís Russomano

Microgravity Centre PUCRS, Brazil

Executive Editor

Rafael Reimann Baptista

Faculdade de Educação Física e Ciências do Desporto, PUCRS, Brazil

e-ISSN: 2179-703X
Corresponding Author:

Lucas dos Santos Boneli <lucasboneli@terra.com.br>

Received: July 01, 2016 Accepted: August 05, 2016

(C) 2016 EDIPUCRS

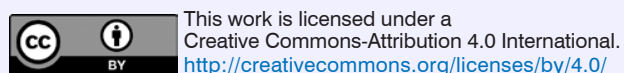




\section{Introdução}

O presente estudo refere-se a uma revisão bibliográfica sobre as perspectivas históricas da aviação no Brasil, destacando principalmente a aviação comercial, posto que a aviação brasileira é subdividida em militar e civil (comercial e privada) (Oliveira, 2008).

A aviação no Brasil embora tenha se apresentado tardiamente, sempre esteve relacionada ao povo brasileiro. No dia 23 de outubro de 1906, quando Alberto Santos Dumont alçou voo no campo de Bagatelle a bordo do seu 14-Bis, ele não só confirmou a possibilidade de um homem voar (Dumont, 2013), mas inseriu o nome do seu país no cenário internacional daquela que pode ser considerada uma das mais importantes invenções do século XX.

Segundo Bielschowsky e Custódio (2011), o transporte aéreo despontou no Brasil apenas na década de 1920, sendo dominado por duas subsidiárias de empresas estrangeiras - a Compagnie Générale Aéropostale (que mais tarde se une ao grupo Air France) e a Condor Syndikat. É importante ressaltar que nesta época o setor aéreo no mundo todo transportava quase que exclusivamente cartas, devido ao tamanho das aeronaves e ao peso da correspondência; o transporte de passageiros será deflagrado apenas no período pós-Segunda Guerra Mundial.

A empresa Condor Syndikat foi fundada na Alemanha no dia 25 de maio de 1924, resultado de um consórcio formado pela Deutscher Aero Lloyd A.G., pela agência mercantil SchlubachTheimer e pela Sociedad Colombo-Alemaña de Transportes Aéreos (Ribeiro, 2008). O empreendedorismo da Condor no Brasil foi uma estratégia da Alemanha para escapar das sanções do Tratado de Versalhes, o qual impôs à nação alemã, além de uma severa multa de 33 bilhões de dólares, a obrigatoriedade de redução da sua frota aérea no que tange a capacidade do motor e ao número de aeronaves. Posteriormente, no ano de 1943 (auge da Segunda Guerra Mundial), quando o Brasil se une aos Aliados e declara guerra aos países do Eixo (Alemanha, Itália e Japão), a empresa é obrigada a trocar de nome, passando a se chamar "Serviços Aéreos Cruzeiro do Sul Ltda”, uma vez que diretores e funcionários de origem alemã foram perseguidos e presos (Ribeiro, 2008).

A Compagnie Générale Aéropostale, que antes se chamava Lignes Aérinnes Latécoere até 1927 (Ferreira, 2013), estabeleceu no fim da década de 1920 uma rota de correio aéreo que saía de Paris, passava pela Espanha, norte da África, Brasil e terminava na Argentina. No Brasil, a presença da empresa foi de suma importância para a ligação inicial de grande parte da costa leste do país (Recife-Pelotas) e também pela construção dos primeiros campos de pouso (Fay, 2013), uma vez que os alemães apenas operavam hidroaviões, excluindo a necessidade de pistas terrestres.

Ainda em 1927, com capital e equipamento alemão, surge a primeira empresa aérea nacional, a VARIG (Viação Aérea Riograndense S/A), coincidindo com o início do processo de modernização econômica do país inaugurado pelo então presidente Getúlio Vargas (Ribeiro, 2008). Fundada por Otto Ernst Meyer Labastille, um ex-oficial do Serviço Aeronáutico alemão, no Rio Grande do Sul, foi uma empresa de caráter inicialmente regional que chegou em seu auge ao patamar de uma das empresas mais importantes do transporte aéreo mundial, chegando a operar rotas para as Américas, África, Europa e Ásia (mapa de rotas, disponível em: <www.varig-airlines.com $>$. Acesso em: 7 abr. 2016). Em 2006, infelizmente, a empresa encerra suas atividades devido a má gestão e corporativismo da Fundação Rubem Berta, que era a controladora da empresa, à crise cambial que assolou o país, à abertura do mercado de aviação para outras empresas nacionais e internacionais, e à forte pressão política (Ribeiro, 2008).

Outra grande empresa a levar a nacionalidade brasileira em sua fuselagem foi a Panair do Brasil. Inicialmente chamada de Nyrba (uma referência a sua primeira rota, Nova Iorque-Rio de Janeiro-Buenos Aires), foi uma empresa inicialmente subsidiária da norte-americana Pan American Airways, que tinha como objetivo parar o crescimento alemão na América do Sul (existiam empresas de capital alemão no Brasil, Colômbia, Equador, Bolívia e Peru). Segundo Ribeiro (2008), a empresa tornou-se uma das maiores empresas brasileiras no pós-guerra, possuindo inclusive uma linha subsidiada na rota do Rio Amazonas, onde transportava remédios, alimentos e vacinas. Já na década de 40, começa a operar linhas com destino a Europa e torna-se a oitava maior companhia aérea do mundo (Castro e Lamy, 1993). Amargamente, em 9 de fevereiro de 1965, o governo militar que se fazia presente no país, retira a concessão de voo da empresa alegando incapacidade financeira e administrativa da mesma e repassa suas rotas para a VARIG (Ribeiro, 2008).

O CAN (Correio Aéreo Nacional) foi outra empresa de importância para o início da aviação brasileira, era composto por pilotos militares que desbravavam o interior do país, construindo campos de pouso e aeródromos por onde passavam (Castro e Lamy, 1993).

Ainda é possível elencar como grandes empresas do passado a VASP (Viação Aérea São Paulo), a Real (Redes Estaduais Aéreas Ltda) e a Transbrasil SA Linhas Aéreas; no setor regional destacaram-se a 
Nordeste Linhas Aéreas, a TAM (Transportes Aéreas Regionais S/A), a Rio-Sul Serviços Aéreos Regionais e a TABA (Transportes Aéreos da Bacia Amazônica). Segundo Malagutti, no período pós-Segunda Guerra, chegaram a ser criadas mais de 20 empresas aéreas nacionais que, atuando em um mercado restrito de passageiros, acabaram tendo que fechar as portas ou serem absorvidas por empresas maiores, logo em seguida.

A medida que novas empresas eram criadas, a competitividade entre as mesmas era cada vez mais notório. O Ministério da Aeronáutica juntamente com o DAC (Departamento da Aviação Civil que, em 2005, virou a ANAC) eram os responsáveis por promover a concessão das rotas como também por delimitar uma tarifa máxima e mínima de passagem que as empresas poderiam cobrar (Salgado e Mota, 2005), assim protegiam o consumidor garantindo-lhe a opção de escolha, uma vez que as rotas teoricamente não eram monopolizadas, e também não permitindo passagens com preços abusivos; Segundo Fay (2002), na década de 50 foi-se inclusive proposta a criação de uma única empresa aérea nacional, a Aerobrás, contudo a iniciativa embarrou na forte pressão contrária do capital privado e acabou sendo abandonada. Entretanto, na década de 90 quando houve a desregulamentação do setor aéreo (Castro e Larny, 1993), a abertura para a livre concorrência acabou permitindo a competição ruinosa que progressivamente se estabeleceu entre as empresas aéreas, na qual passou a se cobrar preços a baixo do normal com o objetivo de retirar o passageiro da empresa concorrente. Contudo, essa tática acabava por deixar a própria empresa endividada.

Posto isso, ao longo da história da aviação brasileira, muitas empresas acabaram se endividando e algumas até encerrando suas operações devido ao estabelecimento dessa competição predatória. Contudo, esse panorama persiste até os dias atuais, sendo comprovado pela atual operação no vermelho das companhias nacionais, levando inclusive a recentes fusões com empresas estrangeiras. Diante desse cenário de "autodestruição", faz-se necessário um estudo de como o órgão regulador permitiu o estabelecimento dessas hostis estratégias, bem como uma rápida análise do mercado aéreo atualmente e possíveis soluções para a questão.

\section{Objetivo}

A presente pesquisa busca, a partir de um viés histórico, demonstrar como se estabeleceu o modelo de competição do mercado da aviação no país juntamente com os seus reflexos, como a atual competição ruinosa estabelecida, através da análise das companhias aéreas do passado e do presente.

\subsection{Objetivos específicos}

- Compreender a atual competição ruinosa no mercado da aviação brasileira, comparando-a com o início da aviação comercial no país;

- descrever os fatos históricos referentes a legislação da aviação brasileira;

- descrever a modificação na regulação aérea brasileira;

- contextualizar o perfil das empresas aéreas brasileiras nos dias atuais.

\section{Os processos regulatórios}

Segundo Oliveira (2008), a aviação comercial no Brasil passou por duas grandes reformas regulatórias, uma primeira entre 1960 e 1970 e uma segunda no início da década de 90, além da substituição do órgão regulador do setor em 2005.

$\bigcirc$ primeiro grande marco regulatório do setor estabeleceu um regime de competição controlada, em que o transporte regular teria que seguir as normas estabelecidas pelo governo e o DAC teria a jurisdição para modificar rotas, frequências e tarifas de serviço (Castro e Larny, 1993). O artigo 8o do Decreto no 38 inclusive previa a competição ruinosa que se estabeleceria entre as empresas, para tanto proibia a concorrência entre as mesmas pelo método da concessão de descontos. Os próprios índices tarifários eram fixados pelo DAC, segundo os artigos $3^{\circ}$ e $4^{\circ}$ do mesmo Decreto.

O segundo marco regulatório, deflagrado na década de 90, foi efetivado dentro do "Programa Federal de Desregulamentação" do Governo Collor, o qual ficou conhecido como Política de Flexibilização da Aviação Comercial Brasileira (Oliveira, 2008). Tal desregulamentação ocorreu de forma gradual, sendo dividida em 3 etapas. A primeira, chamada de Primeira Rodada de Liberalização, acabou com os monopólios regionais permitindo a entrada de novas empresas, o que resultou no aumento da oferta de voos e no número de cidades servidas, o qual passou para aproximadamente 200. Outra medida adotada nessa primeira rodada foi a implementação de uma margem de preço em que as empresas poderiam atuar, que, segundo Oliveira (2010), correspondia a um valor máximo de 50\% do valor principal e um valor mínimo de 32\% do mesmo.

Em fins de 1997 foi lançada a Segunda Rodada de Liberalização, a qual representou o início da "guerra de passagens e frequências". Nessa rodada foram adotadas a retirada das bandeiras tarifárias como também a 
exclusividade das empresas regionais de operarem os chamados "Voos Direto ao Centro", que eram rotas entre aeroportos centrais (com exceção da ponte aérea Rio-São Paulo) realizadas sem escalas. Segundo Castro e Larny (1993), mesmos com as medidas adotadas, as empresas aéreas encontravam-se diante de uma situação ambígua, se por um lado tinham uma relativa flexibilização nas tarifas, por outro permaneciam presas ao esquema de concessão das rotas, o qual não era compatível com a utilização das aeronaves wide-bodies que progressivamente estavam aparecendo nas empresas aéreas nacionais.

Sendo assim, já no início dos anos 2000, foi lançada a Terceira Rodada de Liberalização, também chamada de Quase-Desregulação. Nessa fase foram inicialmente retirados quase todos os mecanismos de regulação que ainda persistiam, o que acabou culminando no aparecimento de novas companhias aéreas (como por exemplo a Gol Transportes Aéreos LTDA) e novos pedidos de rotas e frequências. Entretanto em 2003, com o acirramento da competição ruinosa, o governo federal voltou atrás e passou a exigir um estudo de viabilidade econômica prévia da nova operação requisitada através do DAC. Por isso esse período passou a receber o nome de "Re-regulação".

Tais processos buscaram seguir a política de livre concorrência que se fazia presente no mercado geral brasileiro e também no mundo, para assim "testar" o comportamento das empresas aéreas nacionais diante de um futuro mercado completamente liberal. Contudo, já nessa primeira experiência muitas empresas passaram a se endividar devido à competição. Segundo Castro e Larny (1993), 25\% das passagens passaram a ser vendidas de modo promocional, além disso, empresas que antes tinham o monopólio de certas rotas, como foi o caso da VARIG, passaram a competir com as novas empresas, que foram sendo criadas, através do serviço de bordo de qualidade, porém, sem aumento no custo da passagem, o que levava cada voo da empresa a decolar com deficit. Outra questão agravante foi a relutância das empresas em não diminuir as frequências com medo de perder o cliente para a concorrente, tal fato era perceptível em aeronaves de diferentes empresas decolando quase no mesmo horário, dos mesmos aeroportos com os mesmos destinos e consequentemente, ambas sem a sua lotação máxima. Todavia, a desregulamentação do setor continuou com a criação da ANAC (Agência Nacional de Aviação Civil), promulgada pela Lei no 11.172, de 27 de setembro de 2005 que, segundo Oliveira (2010), surgiu para consagrar os conceitos de liberdade tarifária, livre acesso e livre mobilidade para assim concluir os objetivos iniciais da Política de Flexibilização.

\section{ANAC - Agência Nacional de Aviação Civil}

Em 27 de setembro de 2005, com a extinção do DAC e a criação da ANAC, a política de flexibilização do setor aéreo como também o "controle" do mesmo passou então para as mãos de civis, uma vez que o DAC pertencia ao Ministério da Aeronáutica que era controlado por militares (Malagutti, 2001). Segundo a Lei número 11.172 que sancionou a criação da agência, a mesma opera sob regime de autarquia especial (tendo independência administrativa e autonomia financeira) vinculada ao Ministério da Defesa, sendo responsável por implementar as diretrizes estabelecidas pelo CONAC (Conselho de Aviação Civil), regular e fiscalizar as atividades da aviação civil como também da infraestrutura aeroportuária (Cravo, 2014).

Com a desregulamentação do setor já consolidada no período do DAC, a ANAC passou apenas a exercer uma certa influência na frequência de voos das empresas aéreas, principalmente nos aeroportos centrais do país (conhecidos como aeroportos coordenados), através da política de alocação de slots pois, segundo Cravo (2014), a concessão de slots é o que vai garantir poder de mercado às empresas, visto que o mesmo está inclusive relacionado a fusão e compra de companhias aéreas, como por exemplo na aquisição da VARIG pela GOL.

Slot, no setor aéreo, diz respeito ao intervalo de tempo entre o pouso e a decolagem de uma aeronave, que foi "reservado" a uma empresa aérea por uma agência governamental, mas o mesmo não a pertence. O problema são os aeroportos saturados do país, como por exemplo Congonhas, em que todos os slots já estão ocupados, sendo assim novas empresas que venham a surgir não conseguirão operar nesses aeroportos de maior lucratividade, o que acaba por contradizer os objetivos da ANAC de distribuir os recursos de maneira justa e de promover a competição entre as empresas para assim conceder poder de escolha aos passageiros (Cravo, 2014).

Desta maneira a regulação da agência no que tange a competição entre as empresas se resume apenas à concessão dos slots. A questão da tarifa aérea, por outro lado, nunca mais retornou à "mesa de preocupações" da entidade, ficando agora a critério das próprias empresas (Braga, 2009).

\section{As principais empresas aéreas da atualidade e seu perfil de participação no mercado aéreo brasileiro}

O número de empresas aéreas nacionais em operação, registrou em sua história dois momentos com 
números expressivos, mas também inconvenientes para a demanda da época. $\mathrm{O}$ primeiro deles ocorreu por volta dos anos de 1945, no fim da Segunda Guerra Mundial, quando o país chegou a registrar mais de 20 companhias aéreas. O segundo momento ocorreu após a desregulamentação do setor, por volta dos anos 2000, quando houve um expressivo aumento das companhias de Transporte Aéreo não-regular e de linhas regionais, nesse momento o DAC chegou a registrar aproximadamente 30 companhias em operação no país (Malagutti, 2001).

Atualmente operam no país 4 grandes empresas de transporte aéreo comercial e outras 4 empresas de menor magnitude. A seguir será exposto uma análise da atuação das grandes companhias do setor:

\subsection{GOL Transportes Aéreos LTDA}

A companhia foi fundada no dia 1 de agosto de 2000 e iniciou suas operações em janeiro de 2001, tendo revolucionado o mercado aéreo brasileiro da época (Anjos, 2015). A empresa foi a primeira a trazer o modelo de operação da americana Southwest Airlines para o país e também para a América Latina, tratava-se do modelo de empresa lowcost (baixo custo). Tal forma de operação baseia-se na redução de gastos operacionais para reduzir o preço da tarifa aérea e assim popularizar o transporte aéreo; uma prova dessa pretensão da companhia de popularização do transporte é uma loja física da empresa localizada dentro da estação Trensurb em Porto Alegre. Segundo Anjos (2015), são características desse modelo de atuação: a utilização de uma frota homogênea (no caso da Gol, as aeronaves Boeing 737-700 e 737-800), simplicidade no serviço de bordo (geralmente apenas um pequeno snack), alta densidade de assentos (diminui-se o espaçamento entre as fileiras para aumentar o número de poltronas), e atuação em aeroportos periféricos (pequenos e com baixas taxas de pouso); sendo esta última característica contribuinte para que haja uma contradição no objetivo da companhia de ser uma verdadeira empresa lowcost, uma vez que a empresa opera nos principais aeroportos do país.

Segundo Pereira, J.A. e B.V.N.Y (2011), trata-se de uma empresa do tipo holding tendo como subsidiárias a VRG, a GOL Finance Cayman, a GAC Inc., a Sky Finance e a Sky Finance II. Atualmente a companhia atende cerca de 73 destinos entre nacionais e internacionais com aproximadamente 900 voos diários, segundo últimos dados divulgados pela ABEAR (www. abear.com.br/, acesso em 08 de junho), Associação Brasileira das Empresas Aéreas, fato esse que a colocou em 2014 na primeira posição em participação do mercado doméstico (cerca de 38\%) e terceiro lugar no mercado internacional (cerca de 14\%).

\subsection{Azul Linhas Aéreas Brasileiras S.A.}

Fundada em 2008 pelo empresário brasileiro e estadunidense David Neeleman, é outra companhia que cresceu seguindo o modelo low-cost e aos poucos foi perdendo essas características. Iniciou suas operações no abandonado Aeroporto Internacional de Viracopos, localizado em Campinas, interior de São Paulo, onde estabeleceu seu $h u b$, contribuindo para o crescimento do aeroporto e da região de Campinas; hoje seu terminal de cargas, por exemplo, é considerado o maior da América do Sul, além de o aeroporto ter quintuplicado o número de decolagens diárias após a vinda da companhia.

Antes mesmo de ser fundada, a companhia já mostrava sua proposta de ser uma empresa aérea diferenciada, o próprio nome da empresa foi obtido a partir de uma votação pública (Braga, 2009). Inicialmente operou em aeroportos que até então não eram servidos pelas grandes companhias aéreas, como por exemplo o Aeroporto Internacional João Simões Lopes Neto, em Pelotas, Rio Grande do Sul. Embora não apresente baixas tarifas aéreas como sua concorrente direta, sempre enfatizou seu objetivo de proporcionar a melhor viagem a seus passageiros, como opções variadas de snacks, maior distância entre os assentos e entretenimento a bordo de todas as suas aeronaves, características essas que levaram a empresa em 2015, a ser eleita pela $5^{\mathrm{a}}$ vez consecutiva a melhor companhia aérea lowcost da América do Sul pela Skytrax World Airline Award (www.voeazul.com.br/, acesso em: 10 de junho).

Segundo os últimos dados divulgados pela ABEAR (www.abear.com.br/, acesso em: 10 de junho), a Azul possui a malha aérea mais abrangente do país (cerca de 100 destinos) com uma operação de aproximadamente 900 voos diários, conjuntura essa que a colocou como terceira maior companhia aérea do país tendo participação de 16\% no mercado doméstico e de $15 \%$ no mercado internacional.

\subsection{TAM Linhas Aéreas}

Inicialmente operando sob o nome de Táxi Aéreo Marília, na década de 60, passou a se chamar TAM Linhas Aéreas em 1976 quando o então comandante Rolim Amaro assumiu a diretoria da empresa (www. latam.com/, acesso em: 15 de junho). Diferentemente das suas concorrentes diretas, não busca conquistar o passageiro pelo preço da passagem, mas sim pelo serviço de bordo especializado. 
Pode-se dizer que um dos grandes momentos da empresa ocorreu em 2006, quando sua principal concorrente, a VARIG (Viação Aérea Riograndense $\mathrm{S} / \mathrm{A}$ ), fechou as portas e consequentemente colocou a TAM como maior companhia aérea do país. Segundo o site da empresa (www.latam.com/, acesso em: 15 de junho), é nesse momento que iniciam-se novas rotas da mesma para vários países da Europa e aumentase o número de frequências para os Estados Unidos, principalmente para a cidade de Nova Iorque.

Segundo dados da ABEAR (www.abear.com.br/, acesso em: 17 de junho), em 2015 a empresa, já consolidada como maior aérea do país sobretudo nas linhas internacionais, registrou uma participação de $37 \%$ na demanda do mercado doméstico, um pouco abaixo da participação da GOL como já mencionado, e de aproximadamente 70\% no mercado internacional, em virtude de sua extensa malha aérea internacional com aproximadamente 20 destinos próprios.

Recentemente a empresa se uniu a companhia chilena LAN Airlines formando a LATAM Airlines Group S.A., a qual se tornou o maior grupo da América Latina em malha aérea, atendendo cerca de 135 destinos em 24 países (www.abear.com.br/, acesso em: 17 de junho). Embora a associação entre as empresas tenha ocorrido em 2012, é apenas em 2016 que iniciase a extinção das marcas TAM e LAN em substituição á LATAM (economia.estadao.com.br/, acesso em: 17 de junho). Segundo Vieira, Calicchio e Ziller (2014), essa união busca um posicionamento estratégico das empresas tanto no mercado aéreo da América Latina como também no mercado internacional.

\subsection{Avianca Brasil}

A atual empresa Avianca Brasil foi fundada em 1998 pelo grupo empresarial brasileiro Synergy Group. Antigamente era conhecida como Ocean Air Linhas Aéreas S/A até o ano de 2010 quando então passou a ser chamada de Avianca, em virtude da compra dessa empresa, a Avianca, em 2004, que era colombiana e pertencia ao empresário Julio Mario Santo Domingo e ao grupo Bavaria, assim como todas as empresas que pertenciam a esse grupo (Avianca Cargo, Tampa Cargo, Aerogal, entre outras), pelo Synergy Group, que pertence ao empresário paulista José Efromovich (www. portalbrasil.net/, acesso em: 22 de junho). Em 2010 então, o empresário troca o nome de todas as empresas para unicamente Avianca e anuncia a compra de novas aeronaves do modelo Airbus A-319 para a companhia brasileira, as quais mais tarde viriam a substituir os antigos Fokker-100 ou também conhecidos como MK28 (oglobo.globo.com/, acesso em: 22 de junho).
Assim como a LATAM (ex-TAM), a Avianca não é conhecida por adotar políticas de low fare (baixa tarifa), mas sim por priorizar o conforto de seus passageiros, através da pontualidade, da modernidade da sua frota, do serviço de bordo diferenciado e do entretenimento a bordo. Fato esse comprovado por ter sido a primeira empresa no Brasil a receber da ANAC o selo "A", em virtude da distância entre as poltronas nas suas aeronaves (www.abear.com.br/, acesso em: 22 de junho).

Atualmente a empresa serve 21 destinos, localizados principalmente na região Nordeste do país e tendo o Aeroporto Internacional Juscelino Kubitschek, em Brasília, como seu hub. Segundo dados da ABEAR (www.abear.com.br/, acesso em: 22 de junho), no início de 2015 a empresa obteve participação de apenas 8\% no mercado doméstico e menos de $1 \%$ no mercado internacional. Embora não apresente números muito expressivos, a companhia vem ganhando espaço no mercado ao longo dos anos, segundo a revista Época Negócios, por exemplo, em maio de 2014 a Avianca foi a empresa que apresentou o maior crescimento na demanda doméstica dentre as companhias aéreas do país (epocanegocios.globo.com/, acesso em: 22 de junho).

\section{Metodologia}

O presente estudo foi elaborado entre os meses de abril a julho de 2016, tendo como plataformas de pesquisa: o Google Acadêmico e alguns sites ligados a aviação brasileira. Para tanto, utilizou-se as seguintes palavras-chave: Aviação; ANAC; Brasil; VARIG; Santos Dumont; regulação; desregulação; setor aéreo; aviação civil; transporte aéreo; Azul; LATAM; GOL; evolução; Condor; crise. As quais resultaram em um total de 24 artigos, dos quais 2 foram descartados por não agregarem conteúdo a este referencial, e que não continham as palavras-chave em seu título e resumo. Sendo assim, chegou-se ao seguinte fluxograma:

Figura 1. Fluxograma resultante da pesquisa (Autor)

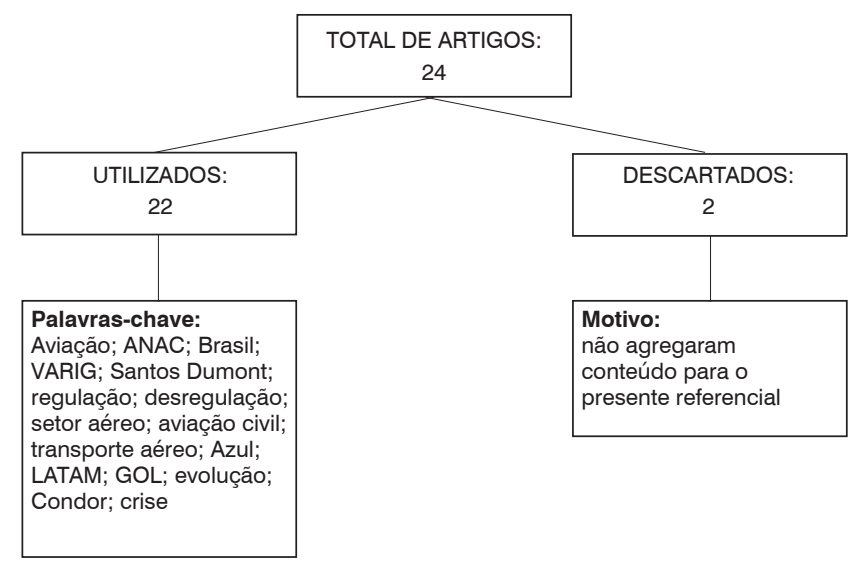




\section{Resultados e Discussão}

Apesar de se tratar de um assunto muito importante para o setor da aviação no Brasil, foi-se constatado uma carência sobre o tema entre os meios de disseminação de conteúdo (artigos, revistas, livros, etc.). Dentre os 22 artigos científicos utilizados no estudo, apenas 8 tratam especificamente sobre essa questão; inclusive alguns autores também mencionaram esta insuficiência de material como fator preocupante.

A partir da leitura desses autores, pode-se perceber uma divergência quanto a instalação da competitividade no setor aéreo, alguns apontam-na como saudável e importante para a universalização do setor, enquanto outros autores elencam na como possível contribuinte das crises do setor, agregada à problemas de gestão e políticas econômicas. Contudo, todos os autores veem a necessidade de um novo marco regulatório para o setor, bem como análises políticas mais profundas na questão.

\section{Conclusão}

A aviação em si sempre representou um motivo de orgulho e entusiasmo para os brasileiros. Embora, atualmente, o transporte aéreo não fomente mais tanta emoção nas pessoas como foi no princípio, ainda há aqueles que apreciam uma bela decolagem ou até mesmo uma visão panorâmica privilegiada. Sendo assim, é exatamente nesse cenário que a competição predatória "mancha" a imagem de um setor que, em um passado recente, só representava alegrias e realizações para aqueles que o utilizavam e o admiravam.

A partir do exposto, pode-se concluir então que sempre houve uma preocupação do governo em relação à competição ruinosa do setor aéreo. Durante a maior parte da existência do DAC (Departamento de Aviação Civil), essa preocupação teve reflexo no extremo controle que se fazia em cima das empresas aéreas da época. Contudo, com o aparecimento da nova política de afastamento do Estado de questões econômicas e a abertura do mercado à iniciativa privada que emergia progressivamente no mundo, principalmente nos Estados Unidos a partir de 1978, o governo passa a desregulamentar o setor e permitir o aparecimento da concorrência. A teoria em si é muito interessante e muito valida, o problema ocorreu que na prática essa competição tornou-se predatória e passou a desestabilizar o setor, fato esse comprovado pelo endividamento de várias empresas aéreas brasileiras, levando até mesmo ao fechamento de algumas ao longo da história. O interessante é que mesmo nos primeiros "testes" da desregulamentação do setor, o problema da competição ruinosa apareceu mas não impediu as entidades responsáveis de prosseguirem com o processo de retirada destes mecanismos de controle, sendo a taxação tarifária o principal deles.

O problema da competição ruinosa é que ela prejudica até mesmo a empresa que está, teoricamente, se beneficiando com ela. O pensamento é simples, primeiramente ocorre a oferta de valores irrisórios para o serviço, com isso uma grande leva de passageiros passa a procurar essa oferta, consequentemente esvaziando as aeronaves das companhias em que eles voavam anteriormente, com isso, a companhia fecha e passa a se ter um monopólio do serviço, assim a empresa sobrevivente amplifica o valor da tarifa com o intuito de repor o prejuízo. O problema é que o passageiro se "acostuma" com aquele baixo preço e no momento em que o mesmo aumenta, ele deixa de utilizar esse serviço se não houver extrema necessidade, por conseguinte a empresa não consegue aumentar sua receita e entra em crise.

Infelizmente esse cenário ocorre cada vez mais na aviação brasileira, mas por vezes não é perceptível. Um trecho Porto Alegre - São Paulo, por exemplo, já apresentou tarifas de 50 reais o trecho (aproximadamente $900 \mathrm{~km}$ ), o que é inconcebível para um serviço que possui tantas despesas; em cada aeronave que decola, a empresa paga tarifa de pouso, tarifa de uso das comunicações, serviço de limpeza, combustível, manutenção e ainda os salários da tripulação e do pessoal de solo. Em uma simples comparação de preço, um passageiro poderia trocar um jantar em um restaurante por uma passagem aérea, o que é paradoxal.

Além disso, pode-se constatar um novo público alvo das companhias aéreas. Durante décadas o transporte aéreo foi uma realidade de apenas uma classe privilegiada, mas hoje em dia essa concepção mudou. Com o surgimento das aeronaves wide-body (corpo largo) o transporte aéreo se popularizou através da diminuição do preço da passagem, viabilizada por esse tipo de aeronave devido a maior oferta de assentos, e com as facilitações de compra que as empresas passaram a proporcionar como, por exemplo, o parcelamento. Como resultado é possível observar uma tendência crescente das companhias aéreas de tornar a aviação um transporte de massa, tendo como estímulo a competição.

Sendo assim, a partir da análise apresentada do setor, foi possível concluir que se faz necessária a volta do controle das tarifas aéreas por parte do órgão regulador, visto que essa seria a única maneira de terminar com a atual competição ruinosa estabelecida. A proposta de massificação do setor aéreo, contudo, 
deve permanecer, porém, respeitando os preços que o serviço aéreo demanda. Uma possível solução para isso seria, por exemplo, a diminuição da carga tributária do setor que, curiosamente, é maior do que a norte-americana e do que a europeia, ou seja, regiões "símbolo" da popularização do transporte aéreo.

\section{Referências}

1. SALGADO, Lucia Helena; MOTTA, Ronaldo Serôa da. Marcos regulatórios no Brasil: o que foi feito e o que falta fazer. Ipea. 2005. Disponível em: <http://hdl.handle. net/11058/3239>. Acesso em: 6 abr. 2016.

2. Elones Fernando Ribeiro. A formação do piloto de linha aérea: caso varig: o ensino aeronáutico acompanhando a evolução tecnológica [tese] [Porto Alegre]: Pontifícia Universidade Católica do Rio Grande do Sul; 2008. 386 p.

3. CAMARGOS, Marcos Antonio; MINADEO, Roberto. Aquisições na aviação civil brasileira: uma análise da trajetória da Gol e da Varig até a sua aquisição. Gestão e Sociedade. 2007; 2. Disponível em: < http://www.oocities. org/wallstreet/exchange/4642/fusoes/GS_GOL_VARIG. pdf>. Acesso em: 6 abr. 2016.

4. BIELSCHOWSKY, Pablo; CUSTÓDIO, Marcos da Cunha. A evolução do setor de transporte aéreo brasileiro. Novo Enfoque. 2011; 13:e72-93. Disponível em: < http://www. castelobranco.br/sistema/novoenfoque/files/13/artigos/7 Prof_Pablo_Marcos_Art4_VF_2.pdf $>$. Acesso em: 8 abr. $201 \overline{6}$.

5. MONTEIRO, Cristiano Fonseca. A Varig e o Brasil entre o desenvolvimento nacional e a competitividade global. Civitas. 2007; 7:e35-58.Disponível em: < http://dx.doi. org/10.15448/1984-7289.2007.1.2036>. Acesso em: 13 abr. 2016.

6. MALAGUTTI, Antônio Osller. Evolução da aviação civil no Brasil. Consultoria Legislativa. 2001. Disponível em: < http://www2.camara.leg.br/documentos-e-pesquisa/ publicacoes/estnottec/arquivos-pdf/pdf/109712.pdf $>$. Acesso em: 14 abr. 2016.

7. DUMONT, Santos. O que eu vi e o que nós veremos [Internet]. Inc. Google. 2013. Disponível em: <https:// books.google.com.br/books?hl=en \&lr $=\& i d=d b t c A A$ AAQBAJ \&oi $=$ fnd \&pg $=$ PA $1889 \& d q=i n f o: t M B v a 2 i E$ aEQJ:scholar.google. $\operatorname{com} \&$ ots $=$ LZ8MHe8f37 \& sig $=$ pl KChf 6 b Th 2 M I p R B s O Z 8 t V x O k \& red ir $\mathrm{esc}=\mathrm{y} \#_{\mathrm{v}}=$ onepage $\& \mathrm{q} \& \mathrm{f}=$ false $>$. Acesso em: $15 \mathrm{abr} .201 \overline{6}$.

8. OLIVEIRA, Alessandro Vinícius Marques de. Regulação da oferta no transporte aéreo: do comportamento de operadoras em mercado liberalizados aos atritos que emergem da interface público-privado. JTL. 2010; 1. Disponível em: $<$ www.transport-literature.org >. Acesso em: 15 abr. 2016.

9. FERREIRA, Mariana. Antoine de Saint-Exupéry e o Campeche: a legitimação de uma história sem registros escritos. Revista Santa Catarina em História.2013; 7:e90103. Disponível em: <http://web.a.ebscohost.com/ehost/ pdfviewer/pdfviewer?sid $=5 \mathrm{f} 40 \mathrm{c} 68 \mathrm{~d}-\mathrm{ba} 1 \mathrm{c}-4 \mathrm{~b} 39-\mathrm{b} 8 \mathrm{fc}-5 \mathrm{~d} 2 \mathrm{f} 7$ $4075334 \% 40$ sessionmgr4001\&vid $=1 \&$ hid $=4207>$. Acesso em: 15 abr. 2016.

10. FAY, Claudia Musa. Crises na aviação brasileira: a ordem internacional e as questões internas. Indic. Econ. FEE. 2002; 30:e124-136. Disponível em: <http://s3. amazonaws.com/academia.edu.documents/33655546/ crises_na_aviacao_brasileira_a_ordem_internacional_e
as_questoes_internas.pdf?AWSAccessKeyId=AKIAJ56 TQ̄JRTWSM̄TNPEA\&Expires $=1467130809 \&$ Signature =X75NzRynVTQM7zSIqNCraELeGIE\%3D\&responsecontent-disposition $=$ inline $\% 3 \mathrm{~B} \% 20$ filename $\% 3 \mathrm{DCrises}$ na_aviacao_brasileira_a_ordem_int.pdf $>$. Acesso em: $2 \overline{0}$ abr. 2016.

11. FAY, Claudia Musa. As viagens de Saint-Exupéry pela América do Sul. Estudos Ibero-Americanos. 2013; 38:e100. 107. Disponível em: <http://revistaseletronicas.pucrs.br/ ojs/index.php/iberoamericana/article/view/12454/8756>. Acesso em: 22 abr. 2016.

12. CASTRO, Newton de; LAMY, Philippe. Desregulamentação do setor transporte o subsetor transporte aéreo de passageiros. Ipea. 1993. Disponível em: < http://hdl.handle. net/11058/2465>. Acesso em: 27 abr. 2016.

13. SALGADO, Lucia Helena. Caos aéreo e tragédia dos comuns: falhas de mercado e de governo. Ipea. 2009. Disponível em: <http://hdl.handle.net/11058/1566>. Acesso em: 27 abr. 2016.

14. OLIVEIRA, Alessandro V. M.; SALGADO, L. H. Reforma regulatória e bem-estar no transporte aéreo brasileiro: e se a flexibilização dos anos 1990 não tivesse ocorrido. NECTAR. 2006. Disponível em: <http://portal3.tcu.gov.br/portal/ page/portal/TCU/comunidades/regulacao/biblioteca digital/ Reforma_regulatoria_no_transp_aereo.pdf $>$. Acesso em: 29 abr. 2016

15. CRAVO, B. M. A alocação de slots e a concorrência no setor de transporte aéreo. JTL. 2014; 8:e159-177. Disponível em: <www.transport-literature.org>. Acesso em: 29 abr. 2016.

16. PEREIRA, Leonardo Porciúncula Gomes; AEROPORTO, Jardim; DE NOVA YORK, Bolsa de Valores. GOL Linhas Aéreas Inteligentes AS [Internet]. 2011. Disponível em: <http://ri.voegol.com.br/arquivos/GOL_20F_2009_port. pdf $>$. Acesso em: 4 maio 2016.

17. ANJOS, Monique Dantas dos. Gol Linhas Aéreas Inteligentes e seu modelo de gestão no mercado aéreo comercial e turístico brasileiro [trabalho de conclusão]. [Niterói]: Universidade Federal Fluminense; 2015. 66 p.

18. FRAZÃO, Jessica Aline Franco. O efeito de empresas de baixo custo sobre a demanda: Estudo comparativo Azul e Gol [tese]. [São José dos Campos]: Instituto Tecnológico de Aeronáutica; 2016. 14 p.

19. Luiz Gustavo Thadeo Braga. O Papel da Agência Nacional de Aviação Civil-ANAC no Fomento da Competitividade entre as Empresas Aéreas de Transporte de Passageiros no Brasil: uma questão de sustentabilidade [dissertação]. [Curitiba]: Centro Universitário Curitiba; 2009. 219 p.

20. VIEIRA, Laís Duarte; CALICCHIO, Antonio Carlos; ZILLER, Moisés Ari. O Caso LATAM: uma fusão como posicionamento estratégico. Ciências Administrativas. 2014; 17. Disponível em: <http://ojs.unifor.br/index.php/ rca/article/view/3257/pdf > . Acesso em: 10 maio 2016.

21. MINADEO, Roberto. Aviação Civil: Classificação de Crises de Companhias Aéreas. Convibra. Disponível em: <http://www.convibra.com.br/upload/paper/2013/32/ 2013_32_7904.pdf>. Acesso em: 12 maio 2016.

22. A evolução do mapa de rotas da Varig [Internet]. Disponível em: < http://www.varig-airlines.com/pt/rotas.htm >. Acesso em: 7 abr. 2016.

23. Associação Brasileira das Empresas Aéreas. Panorama 2014: O setor aéreo em dados e análises [Internet]. Disponível em: < http://www.abear.com.br/uploads/arquivos/dados_e_fatos arquivos_ptbr/ABEAR_Panorama2014_24jul_v2_simples. pdf $>$. Acesso em: 8 jun. 2016. 
24. Associação Brasileira das Empresas Aéreas. Aéreas brasileiras iniciam 2015 com altas expressivas nos mercados doméstico e internacional [Internet]. Disponível em: <http://www. abear.com.br/imprensa/notas-e-releases/mostrar/aereasbrasileiras-iniciam-2015-com-altas-expressivas-nosmercados-domestico-e-internacional $>$. Acesso em: 8 jun. 2016.

25. AZUL. História e origem [Internet]. Disponível em: < http:// www.voeazul.com.br/sobre-azul >. Acesso em: 10 jun. 2016.

26. LATAM Airlines. Uma trajetória de sucesso e de crescimento [Internet]. Disponível em: < https://www.latam.com/pt_br/ conheca-nos/sobre-nos/historia/>. Acesso em: 15 jun. $2 \overline{0} 16$.

27. GAZZONI, Marina. Estadão. A maratona para trocar as marcas TAM e LAN [Internet]. São Paulo. Disponível em: < http://economia.estadao.com.br/noticias/negocios,a- maratona-para-trocar-as-marcas-tam-e-lan, 1745183>. Acesso em: 17 jun. 2016.

28. Portal Brasil. Avianca Brasil [Internet]. Disponível em: <http://www.portalbrasil.net/aviacao_avianca.htm $>$. Acesso em: 22 jun. 2016.

29. LAGUNA, Eduardo. Valor Online. OceanAir passa a se chamar Avianca [Internet]. Disponível em: <http:// oglobo.globo.com/economia/oceanair-passa-se-chamaravianca-3017885 >. Acesso em: 22 jun. 2016.

30. Época Negócios. Avianca e Gol crescem no mercado doméstico em maio, aponta ANAC [Internet]. Disponível em: $<$ http://epocanegocios.globo.com/Informacao/Resultados/ noticia/2015/06/avianca-e-gol-crescem-no-mercadodomestico-em-maio-aponta-anac.html>. Acesso em: 22 de jun. 2016. 